\title{
Kinetics of the serpentinization reactions: It's about time
}

\author{
HECTOR M. LAMADRID ${ }^{1 *}$, ZOLTAN ZAJACZ ${ }^{2}$, ROBERT J. \\ BODNAR $^{3}$
}

${ }^{1}$ University of Missouri, Columbia, MO 65211, (*correspondance: lamadridh@missouri.edu

${ }^{2}$ Unversity of Geneva, 1205 Geneve, Switzerland (zoltan.zajacz@unige.ch)

${ }^{3}$ Virginia Tech, Blacksburg, VA 24061 (rjb@vt.edu)

Serpentinization, i.e. the hydrothermal alteration of ultramafic rocks, is an integral geologic process that occurs in slow- and ultraslow-spreading mid-ocean ridges, magma-poor passive margins, subduction zones, and in continental settings in obducted ophiolites. In recent years, several studies [1,2] have suggested the possibility that serpentinization of ultramafic rocks is a potential mechanism to aid in the formation of brines and salt deposits where other mechanisms (e.g. evaporation) are inconsistent with geological evidence. While serpentinization consumes water and will increase the salinity of the fluid, recent experimental studies $[3,4]$ have shown that fluid composition and the salinity of the fluid strongly affect the kinetics of the serpentinization reaction. Here, we show results from an experimental study and kinetic modelling of the serpentinization of olivine and pyroxene at different $\mathrm{T}$, fluid compositions (salinities) and reactive surface areas to explore the kinetic factors that control the serpentinization reaction.

Our results indicate that serpentinization rates decrease by several orders of magnitude as fluid salinity and the $\mathrm{CO}_{2}$ and $\mathrm{Mg}^{2+}$ concentrations increase. We constructed a quantitative model based on the principle of detailed balance and the particle lifetime model to predict variations in serpentinization rates and the timing of the serpentinization reaction from ambient temperatures to $320{ }^{\circ} \mathrm{C}$ based on kinetic constraints derived from experiments involving various fluid compositions. The models show that the lifetime of olivine and pyroxene varies from months to 1000s of years in fluids with seawater-like composition, to 100 s to 1000 s of millions of years with high salinity fluids $(\sim 30 \mathrm{wt} . \% \mathrm{NaCl})$.

The kinetics of the serpentinization reaction imposes time constraints on the alteration processes occurring in the mantle and should be considered when developing models to understand the potential role of serpentinization on generation of brines and salt deposits.

[1] Scribano et al. (2017) Int J. Earth Sci., 106, 2595-2608. [2] Debure et al. (2019) Sci. Rep., 9, 1-11. [3] Andreani et al. (2012) Am. Min., 98, 1738-1744. [4] Lamadrid et al. (2017) Nat. Commun., 8, 16107. 